\title{
Role of IV administered Iron sucrose with recombinant erythropoietin in the treatment of moderate and severe iron deficiency anemia in the third trimester of pregnancy
}

\author{
Namrita Sandhu' ${ }^{1}$, Sanjay Singh ${ }^{2 *}$ \\ ${ }^{1}$ Department of Obstetrics and Gynecology, Army College of Medical Sciences Delhi Cantt, Delhi, India \\ ${ }^{2}$ Department of Obstetrics and Gynecology, Base Hospital Delhi Cantt, Delhi, India
}

Received: 29 May 2019

Accepted: 09 July 2019

\section{*Correspondence:}

Dr. Sanjay Singh,

E-mail: drsanjaysingh@gmail.com

Copyright: ( ) the author(s), publisher and licensee Medip Academy. This is an open-access article distributed under the terms of the Creative Commons Attribution Non-Commercial License, which permits unrestricted non-commercial use, distribution, and reproduction in any medium, provided the original work is properly cited.

\section{ABSTRACT}

Background: Iron deficiency Anemia in pregnancy is one of the most common and intractable nutritional problems in the world today. The objective of this study was to investigate the therapeutic efficacy and safety of rHuEPO combined with IV iron sucrose, in the treatment of pregnant women in third trimester with moderate and severe iron deficiency anemia and whether addition of erythropoietin will increase the rate of rise of $\mathrm{Hb}$ without compromising on the safety of the therapy.

Methods: 60 pregnant women in the third trimester, diagnosed as cases of moderate and severe iron deficiency anemia were enrolled in this study with 30 subjects in each of the 2 groups. Recombinant Erythropoietin $2000 \mathrm{IU}$ s/c and Inj Iron sucrose $100 \mathrm{mg}$ slow intravenously in $100 \mathrm{ml} 0.9 \% \mathrm{NS}$ over $1 \mathrm{hr}$ on alternate days was administered to the case group and the control group was administered only iron sucrose slow IV in the same dose on alternate days till target $\mathrm{Hb}(11 \mathrm{gm} \%)$ was reached. Efficacy measures were reticulocyte count, increase in $\mathrm{Hb} /$ week, time to target $\mathrm{Hb}$ level and need for continued therapy after 4 weeks.

Results: In the case group, the increases in $\mathrm{Hb}$ were greater after 1 week of treatment and this was found to be significant $(\mathrm{P}<.01)$, the median duration of therapy was shorter in the case group ( 22 versus 34 days), with more patients reaching the target hemoglobin level by 4 weeks as opposed to 7 weeks in the control group. Average rise in $\mathrm{Hb} /$ week was much more in the case group. The groups did not differ with respect to maternal and fetal safety parameters.

Conclusions: Iron sucrose plus rhEPO is an effective treatment for iron deficiency anemia in pregnancy probably because of a synergistic action, with rhEPO stimulating erythropoiesis and iron sucrose delivering iron for hemoglobin synthesis.

Keywords: Haemoglobin, Inj Iron sucrose, Iron deficiency anemia, Recombinant Erythropoietin, Reticulocyte count, Serum Ferritin, Third trimester pregnancy

\section{INTRODUCTION}

Iron deficiency Anemia in pregnancy is one of the most common and intractable nutritional problems in the world today. Oral supplementation due to its low cost and high effectiveness has been the treatment of choice in Iron deficiency anemia (IDA). ${ }^{1}$ However, alternate therapies become necessary due to the inability to tolerate side effects of oral iron, noncompliance, documented iron malabsorption and pregnancies near term. ${ }^{2}$ Blood 
transfusion, though has been widely used, comes with its own set of complications. ${ }^{3,4}$

Parenteral administration of iron is the only effective therapy to supply enough iron for erythropoiesis. Singh et al reported a faster increase in hemoglobin, ferritin and iron stores by intravenous iron therapy. ${ }^{5}$ During the last decade, rHuEPO supplementation has also been used in the treatment of anemia in pregnancy and post partum. 6

In cases of severe anemia of pregnancy, with the threat of mortality and morbidity looming large, safe and effective treatment is mandatory. This has been the motivation in genesis of this study, the objective of which is to investigate the therapeutic efficacy and safety of rHuEPO combined with IV iron sucrose, in the treatment of pregnant women in third trimester of pregnancy with moderate and severe iron deficiency anemia and whether addition of erythropoietin will increase the rate of rise of $\mathrm{Hb}$ without compromising on the safety of the therapy.

\section{METHODS}

A prospective case control study was conducted at a tertiary care centre over a period of 2 years i.e. from August 2009 to August 2011, after taking approval from the ethical committee of our hospital. A total of 60 pregnant women in the third trimester booked at our antenatal clinic, who were diagnosed as cases of moderate and severe iron deficiency anemia and who fulfilled our clinical criteria were enrolled in this study. There were 2 groups, case and control group with 30 subjects in each group. All patients had received oral iron supplements ( $80 \mathrm{mg}$ iron sulfate daily) on a routine basis since the beginning of the second trimester, but developed anemia. Minimum duration of oral iron supplementation was 4 weeks, before intravenous therapy was commenced.

\section{Inclusion criteria}

- $\quad$ Age 18-45 years old

- Singleton pregnancy between 29 weeks to 36 weeks gestation

- $\mathrm{Hb}<8.1 \mathrm{~g} / \mathrm{dL}$ and $>5.0 \mathrm{gm} / \mathrm{dl}$

- $\mathrm{MCV}<80 \mathrm{fl}$

- $\mathrm{MCH}<27 \mathrm{pg}$

- $\mathrm{MCHC}<34 \mathrm{~g} / \mathrm{dl}$

- Normal Hb electrophoresis

- Peripheral blood smear suggestive of iron deficiency anemia

- With no co-morbidities, e.g. hypertension, gestational diabetes mellitus, heart disease, peptic ulcer etc.

- Giving consent and having signed the consent form for this study.

\section{Exclusion criteria}

- $\quad \mathrm{Hb}>8 \mathrm{gm} / \mathrm{dl}$ and $\mathrm{Hb}<5 \mathrm{gm} / \mathrm{dl}$
- $\quad$ C-reactive protein $>3 \mathrm{mg} / \mathrm{L}$

- Serum ferritin $>15 \mathrm{mcg} / \mathrm{L}$

- $\mathrm{MCV}>80 \mathrm{fl}$

- $\mathrm{MCHC}>34 \mathrm{gm} / \mathrm{dl}$

- $\mathrm{MCH}>27 \mathrm{pg}$

- PBS: any other type of anemia other than microcytic hypochromic anemia

- History of allergy to iron containing medication

- History of any other allergic condition or asthma

- History of bleeding tendency

- History of blood transfusion within the last 120 days

- History of delivery before 36 weeks gestation in previous pregnancies.

The diagnosis of iron deficiency anemia was established by the measurement of the following hematological parameters: Hb, PCV, Serum ferritin, Total iron binding capacity (TIBC), Red blood cell indices (MCV, MCH, and MCHC), Peripheral blood smear (PBS), $\mathrm{Hb}$ electrophoresis and Reticulocyte count. Any other type of anemia other than iron deficiency was excluded. Blood samples were obtained at the initiation of the treatment and weekly thereafter. At the initiation of the treatment, $\mathrm{Hb}, \mathrm{PCV}, \mathrm{MCV}, \mathrm{MCH}, \mathrm{MCHC}$, PBS for typing of anemia, reticulocyte count, serum ferritin, TIBC were sent. Creatinine and blood urea were measured before therapy and 4 to 6 weeks later to exclude nephropathy or possible renal impairment. Liver function tests were assessed. Serum ferritin and serum iron levels were determined at the beginning and after the completion of the therapeutic protocol.

Our therapeutic protocol included administration of Recombinant Erythropoietin $2000 \mathrm{IU}$ s/c and Inj iron sucrose $100 \mathrm{mg}$ slow intravenously in $100 \mathrm{ml} 0.9 \% \mathrm{NS}$ over $1 \mathrm{hr}$ on alternate days to the case group till the target $\mathrm{Hb}(11 \mathrm{gm} \%)$ was reached. The control group was administered only iron sucrose slow IV in the same dose on alternate days till target $\mathrm{Hb}(11 \mathrm{gm} \%)$ was reached.

Formulae used to calculate the iron requirement of the patient to fulfil the deficit as well as to replenish the iron stores was as follows 7

Amount of iron deficit $(\mathrm{mg})=$ [Body wt. $(\mathrm{Kg}) \times \mathrm{Hb}$ deficit $\times 2.4]+1000$

$[\mathrm{Hb}$ deficit $=$ target $\mathrm{Hb}$-initial $\mathrm{Hb}]$

\section{Drug administration}

An 18 gauge cannula was inserted into a forearm vein, and its position was confirmed by flushing with $5 \mathrm{~mL}$ saline solution and aspirating blood. We used Inj iron sucrose (Feronia), 1 ampoule $=5 \mathrm{ml}=100 \mathrm{mg} .100 \mathrm{mg}$ of iron sucrose was added in $100 \mathrm{ml}$ of $0.9 \% \mathrm{NS}$ and administered slowly over a period of $1 \mathrm{hr}$ and the cannula was flushed again with $5 \mathrm{~mL}$ saline solution. Studies have shown that no test dose is required with iron sucrose. ${ }^{8}$ 
Therefore, no test dose was administered. However, patients were observed for 24 hours for the development of any reaction or drug allergy.

In the case group, Inj rhEPO 2000 IU was administered $\mathrm{s} / \mathrm{c}$ in the upper arm on alternate days. Pulse rate and blood pressure were monitored $10 \mathrm{~min}$ before and after administration of injection. In the weekly follow up, $\mathrm{Hb}$ (weekly till target $\mathrm{Hb}$ was met) and reticulocyte count (only for first week) were sent. Hematological parameters were measured using hematology auto analyser, except the reticulocyte count which was performed by manual method with the help of supravital staining. Patients were hospitalized and treated until $\mathrm{Hb}$ concentration either exceeded $9 \mathrm{~g} / \mathrm{dl}$ or reached at least $8 \mathrm{~g} / \mathrm{dl}$ with obvious clinical improvement. Patients with $\mathrm{Hb}$ levels constantly $<8 \mathrm{~g} / \mathrm{dl}$ and patients with anemia related symptoms were given in patient care, whereas patients with $\mathrm{Hb}>8 \mathrm{gm}$ were treated on outpatient basis.

Efficacy measures were reticulocyte count, increase in $\mathrm{Hb} / \mathrm{wk}$, time to target $\mathrm{Hb}$ level (duration of therapy in days/weeks) and need for continued therapy after 4 weeks.

\section{Statistical analysis}

The data was summarized as frequencies or percentages for categorical variables and as means and standard deviations or medians for continuous variables, depending on the distribution. The data was analyzed with the help of SPSS software, version 8.

\section{RESULTS}

The demographic variables (mean age and weight) in both the groups were well matched. The mean $\mathrm{Hb}$, reticulocyte count and the mean ferritin level were comparable in both the groups (Table 1).

Table 1: Demographic characteristic of study population.

\begin{tabular}{|llll|}
\hline $\begin{array}{l}\text { Demographic } \\
\text { variables }\end{array}$ & $\begin{array}{l}\text { Case } \\
\text { group } \\
(30)\end{array}$ & $\begin{array}{l}\text { Control } \\
\text { group } \\
(30)\end{array}$ & $\begin{array}{l}\text { Significant } \\
\text { (P value) }\end{array}$ \\
\hline Mean age (years) & 27.16 & 27.36 & $0.821(\mathrm{~ns})$ \\
\hline Mean Ht (metres) & 1.61 & 1.62 & $0.569(\mathrm{~ns})$ \\
\hline $\begin{array}{l}\text { Mean Wt } \\
\text { (kilograms) }\end{array}$ & 65.03 & 66.2 & $0.475(\mathrm{~ns})$ \\
\hline Mean Hb (gm\%) & 6.69 & 6.72 & $0.897(\mathrm{~ns})$ \\
\hline $\begin{array}{l}\text { Mean retic count } \\
\text { (\%) }\end{array}$ & 1.22 & 1.39 & $0.284(\mathrm{~ns})$ \\
\hline Mean MCV (Fl) & 65.51 & 67.06 & $0.267(\mathrm{~ns})$ \\
\hline $\begin{array}{l}\text { Mean MCH } \\
\text { (picogram) }\end{array}$ & 19.05 & 20.42 & $0.095(\mathrm{~ns})$ \\
\hline Mean MCHC (g/dl) & 25.96 & 26.8 & $0.174(\mathrm{~ns})$ \\
\hline $\begin{array}{l}\text { Mean ferritin } \\
\text { (ng/ml) }\end{array}$ & 7.01 & 7.15 & $0.785(\mathrm{~ns})$ \\
\hline
\end{tabular}

Table 2: Mean and standard deviation of weekly rise in $\mathbf{H b}$.

\begin{tabular}{|c|c|c|c|c|c|}
\hline \multicolumn{6}{|c|}{ Group Statistics } \\
\hline $\mathrm{Hb} \%$ at & Group & $\mathbf{N}$ & Mean & Std. deviation & t value \\
\hline \multirow{2}{*}{ Start } & Case group & 30 & 6.6967 & 0.6360 & 0.131 \\
\hline & Control group & 30 & 6.7200 & 0.7434 & \\
\hline \multirow{2}{*}{1 Week } & Case group & 29 & 8.0621 & 0.8011 & $6.66^{*}$ \\
\hline & Control group & 30 & 6.7200 & 0.7434 & \\
\hline \multirow{2}{*}{2 Weeks } & Case group & 29 & 9.3862 & 0.9368 & $8.388 *$ \\
\hline & Control group & 29 & 7.4724 & 0.7950 & \\
\hline \multirow{2}{*}{3 Weeks } & Case group & 27 & 10.6815 & 0.6599 & $11.71 *$ \\
\hline & Control group & 29 & 8.3414 & 0.8300 & \\
\hline \multirow{2}{*}{4 Weeks } & Case group & 16 & 11.5625 & 0.3879 & $13.42 *$ \\
\hline & Control group & 29 & 9.1690 & 0.8058 & \\
\hline \multirow{2}{*}{5 Weeks } & Case group & 0 (a) & & & \\
\hline & Control group & 28 & 9.9750 & 0.7281 & \\
\hline \multirow{2}{*}{6 Weeks } & Case group & 0 (a) & & & \\
\hline & Control group & 23 & 10.7696 & 0.7320 & \\
\hline \multirow{2}{*}{7 Weeks } & Case group & 0 (a) & & & \\
\hline & Control group & 3 & 11.6667 & 0.4163 & \\
\hline
\end{tabular}

$\mathrm{t}$ value could not be computed after 4 weeks because there is no comparison group left as all patients in the case group met their target $\mathrm{Hb}$. *significant at 0.01 .

The mean $\mathrm{Hb}$ at the start of the therapy in the case group was $6.69 \pm 0.63$ and in the control group was $6.72 \pm 0.74$.
After one week of therapy, the $\mathrm{Hb}$ in the case group rose to 8.06 (The rise was significant at 0.01 ) where as in the 
control group no significant rise was seen in the first week. A consistent rise in $\mathrm{Hb}$ was noted in the case group in the weekly follow up and all 29 responders, (barring one subject who had a reaction) had correction of their anemia within the first 4 weeks of treatment (Table 2).

Table 3: Mean rise of $\mathrm{Hb} /$ week.

\begin{tabular}{|lllll|}
\hline Group & N & $\begin{array}{l}\text { Mean rise } \\
\text { of Hb/week }\end{array}$ & $\begin{array}{l}\text { Std. } \\
\text { deviation }\end{array}$ & $\begin{array}{l}\text { t- } \\
\text { value }\end{array}$ \\
\hline Case group & 29 & 1.3931 & 0.3139 & $8.10^{*}$ \\
\hline Control group & 29 & 0.8572 & 0.1682 & \\
\hline *significant at 0.01. & & & \\
\hline
\end{tabular}

Table 4: Represents time to attain target $\mathrm{Hb}$ in both groups.

\begin{tabular}{|lrlll|}
\hline Group & N & $\begin{array}{l}\text { Time to } \\
\text { attain } \\
\text { target Hb }\end{array}$ & $\begin{array}{l}\text { Std } \\
\text { deviation }\end{array}$ & $\begin{array}{l}\text { t- } \\
\text { value }\end{array}$ \\
\hline Case group & 29 & 21.7586 & 4.5250 & $9.25^{*}$ \\
\hline Control group & 29 & 34.4138 & 5.8096 & \\
\hline *significant at 0.01. & & & \\
\hline
\end{tabular}

However in the control group the initial rise in $\mathrm{Hb}$ was noticed only from the second week, after which the rise was consistent and target $\mathrm{Hb}$ was met by the seventh week. After the fourth week, 29 women were still left in the control group to reach their target $\mathrm{Hb}$. So, $\mathrm{t}$ value could not be compared after 4 weeks as there was no comparison group. In both the groups, 29/30 patients responded to the therapy (one patient in each group had a reaction) and none of the patients required blood transfusion. A much greater rise in the reticulocyte count was observed after the first week of therapy in the case group as compared to the control group (The rise was significant at 0.01 ).

In the case group, a mean rise of $1.3 \mathrm{gm} / \mathrm{dl}$ in the $\mathrm{Hb}$ was noted per week, while in the control group the mean $\mathrm{Hb}$ increased only $0.85 \mathrm{gm} / \mathrm{dl}$ per week. Rise in the case group was found to be significantly more $(p<0.01)$ as compared to the control group. In the case group, the improvement of $\mathrm{Hb}$ concentration was obvious as early as the first week of treatment. The corresponding increase in the control group was much less and became apparent only after the second week (Table 3 ).

In the case group, the target $\mathrm{Hb}$ of $11 \mathrm{gm} \%$ was met in $21.7 \pm 4.5$ days, however in the control group target $\mathrm{Hb}$ was met in $34.4 \pm 5.8$ days (Table 4 ). This difference was also found to be significant $(\mathrm{p}<0.01)$.

Table 5: Represents the adverse effects in both groups.

\begin{tabular}{|llllll|}
\hline Group & N & Infusion reactions & Preterm labour & Need for blood transfusion & Non responders \\
\hline Case group & 29 & 1 & 1 & Nil & Nil \\
\hline Control group & 29 & 1 & 2 & Nil & Nil \\
\hline
\end{tabular}

In our study, 29/30 enrolled women in each of the two groups responded sufficiently to the therapy. One woman in each of the two groups had a reaction to the therapy. So, treatment had to be stopped. However the rest 29 responders in each group had correction of their anemia with no major adverse effects. One patient in the case group and two in the control group went into preterm labour around 36 weeks, after the completion of therapy, however, without neonatal complications. The pregnancy outcome was good in all the other cases. There were no signs of any adverse effect on neonates possibly associated with the therapeutic protocol (Table 5).

Hence, both regimens were effective, but with adjuvant recombinant human erythropoietin, the increases in $\mathrm{Hb}$ were greater after 1 week of treatment and this treatment was found to be significant ( $p<0.01$ ), and the median duration of therapy was shorter ( 22 versus 34 days), with more patients reaching the target hemoglobin level by 4 weeks of treatment in the case group as opposed to 7 weeks in the control group and the average rise in $\mathrm{Hb}$ /week was much more in the case group versus the control group. The groups did not differ with respect to maternal and fetal safety parameters. None of the women needed additional antepartum or postpartum blood transfusion.

\section{DISCUSSION}

This study was conducted to determine the safety and efficacy of IV administered iron sucrose with recombinant erythropoietin in the treatment of moderate or severe iron deficiency anemia in the third trimester of pregnancy. Recent literature suggests that EPO has been successfully used to treat non-renal obstetric anaemia, postpartum anemia, end stage renal disease, as well as anemia of pregnant women with chronic hematological disorders. ${ }^{9-17}$ Retrospective data suggests that combination of adjuvant EPO with parenteral iron sucrose is safe and effective in treatment of iron deficiency anemia in pregnancy.

In a randomized trial of 40 patients (20 case group, 20 control group) with Gestational anemia, Breymann et al, compared the efficacy and safety of intravenously administered iron sucrose with and without adjuvant 
recombinant human erythropoietin for the treatment of resistant iron deficiency anemia during pregnancy. ${ }^{18}$ To the case group Inj iron sucrose and Inj EPO was administered whereas only Inj iron sucrose was administered to the control group. He found both regimens to be effective, but with adjuvant recombinant human erythropoietin the reticulocyte count and hematocrit levels rose faster. Also, more patients reached the target hemoglobin $(11 \mathrm{~g} / \mathrm{dl})$ by 4 weeks of treatment in the combination group than in the group treated only with intravenous iron sucrose.

In another study by Sifaki et al, the efficacy and safety of rHuEPO combined with iron sucrose was tested in 26 pregnant women with iron deficiency for a period of 4 weeks. ${ }^{19}$ Results of this study also favoured the use of rHuEPO with parenteral iron sucrose. This study further discusses issues related to the safety and efficacy of rHuEPO treatment during pregnancy, the attitudes of pregnant women toward treatment options, financial burden of therapy as well as side effect profile of rHuEPO and parenteral iron.

Our study also showed similar results with both groups showing good therapeutic response. However the case group showed remarkable enhancement of erythropoiesis as proved by the significant increase in $\mathrm{Hb}$ noticed from as early as the first week of therapy and target $\mathrm{Hb}$ $(11 \mathrm{gm} \%)$ was achieved in all the patients in case group by 4 weeks of therapy where as patients in the control group took around 7 weeks to reach the target $\mathrm{Hb}$.

As parenterally administered iron sucrose is safe and effective, the combination of the two substances increases the efficacy of anemia therapy by stimulating erythropoiesis at the same time that it delivers enough iron for hemoglobin synthesis and iron stores. It is now generally accepted that $\mathrm{r}$ HhEPO should be combined with parenterally administered iron, especially when iron stores are empty before therapy. ${ }^{20,21}$

Literature has shown that with the administration of high doses of EPO, secondary iron deficiency due to the stimulation of erythropoiesis may result, and this may mask the beneficial effects. Hence, supplementation with iron preparation is imperative.

In the study conducted by Breymann et al on 40 patients, mean $\mathrm{Hb}$ at the start of therapy was $9.0 \pm 0.7$ in group 1 and $9.2 \pm 0.6$ in group 2, mean duration of therapy was 18 days in case group and 25 days in control group. However in our study with 30 patients each in both groups, mean $\mathrm{Hb}$ at the start of therapy was $6.69 \pm 0.63$ in the case group and $6.72 \pm 0.74$ in the control group. Mean duration of therapy in the case group was 22 days and 34 days in the control group.

In the study conducted by Breymann et al, after 4 weeks of therapy only one patient in case group had not reached target $\mathrm{Hb}$ of $11 \mathrm{gm} / \mathrm{dl}$, whereas 5 patients had not done so in the control group. In our study, all patients in the case group reached target $\mathrm{Hb}$ of $11 \mathrm{gm} / \mathrm{dl}$ whereas none of the patients in the control group reached the target $\mathrm{Hb}$ (11 gm\%) in 4 weeks. Time to target $\mathrm{Hb}$ was 7 weeks in the control group. In our study just after one wk of therapy, the $\mathrm{Hb}$ in the case group rose to $8.06 \mathrm{gms}$ whereas in the control group no significant rise was seen in the first week.

In the case group in our study, a consistent rise in $\mathrm{Hb}$ was noted in the weekly follow up and all patients met target $\mathrm{Hb}$ in 4 weeks of treatment. However in the control group the initial rise in $\mathrm{Hb}$ was noticed only from the second week, after which the rise was consistent and target $\mathrm{Hb}$ was met by the seventh week.

In Breymann et al study, case group had higher reticulocyte counts than control group from day 4 of treatment. In our study too, a much greater rise in the reticulocyte count was observed after the first week of therapy in the case group as compared to the control group.

Average rise of $3.17 \mathrm{~g} / \mathrm{dl}$ in $\mathrm{Hb}$ concentration during the total period of therapy of 4 weeks was observed in the study by Sifakis et al, with $3 \mathrm{~g} / \mathrm{dl}$ increase within the first 2 weeks. ${ }^{19}$ In 5 women $(19.2 \%)$ there was no significant increase in $\mathrm{Hb}$ levels, while in 2 women $(7.6 \%)$ a further decline in $\mathrm{Hb}$ concentration was observed that necessitated a blood transfusion. In our study an average rise of $1.3 \mathrm{gm} / \mathrm{dl} /$ week was observed in case group and $0.8 \mathrm{gm} / \mathrm{dl} /$ week in control group. All women responded to the therapy, although the response was slower in the control group.

Despite severe anemia at diagnosis, all patients in the study conducted by Breymann et al, delivered at term with no small for gestational age infants and no blood transfusion requirements. ${ }^{18}$ However in our study, 1 case in the case group and 2 in the control group went into preterm labour. However all delivered healthy appropriate for gestational age babies and with no blood transfusion requirements. In the study conducted by Sifaki et al, low frequency of side effects (allergic reactions) and no severe side effects were observed. ${ }^{19}$ In our study 2 cases of mild allergic reaction were noted, one each in the case and control group.

The dose of EPO used in earlier studies was much higher than that used by us. We used 2000 IU per dose on alternate days till target $\mathrm{Hb}$ was reached. However, in the study conducted by Breymann et al, 18,300IU/kg body wt/dose was used biweekly till target $\mathrm{Hb}$ was met, which would roughly come to $18,000 \mathrm{IU}$ per dose for a $60 \mathrm{~kg}$ lady, much higher than the dose used by us. Sifaki et al used $150 \mathrm{IU} / \mathrm{kg}$ body wt/dose of rHuEPO three times a week, again much more than used by us. Also, with the availability of EPO at an affordable price, the cost of therapy has gone down drastically, thus alleviating the 
cost factor which was a major deterrent for its widespread use in trials.

Future studies are needed to select patients who would most likely benefit from rhEPO. There is already evidence that patients with endogenous erythropoietin levels that are lower than proportional to the grade of anemia may benefit more. Cazzola et al have suggested that endogenous erythropoietin levels $<100 \mathrm{U} / \mathrm{L}$ are disproportionately low for anemia and that such patients should therefore receive erythropoietin supplementation. $^{22}$

On the other hand, there are no reference values for anemia- related endogenous erythropoietin levels during pregnancy. The erythropoietin secretory response to anemia may differ between pregnant and non pregnant states, and erythropoietin levels are dependent on various obstetric conditions, as shown previously by Goldstein et al. ${ }^{23}$

Breyman et al in his study showed no correlation between endogenous erythropoietin level and hematocrit. This finding agrees with previous observations by Beguin et al, and Fuchs et al, who suggested that erythropoietin secretion is blunted in pregnancy, possibly by inhibitory cytokines such as interleukin 1, interleukin 6 , or interferon $\gamma .^{24,25}$ Levels of these cytokines are elevated in pregnancy by activated immune mechanisms, and they inhibit erythropoietin secretion in vivo and in vitro.

In our study we did not study endogenous erythropoietin levels. So, the correlation between endogenous erythropoietin levels and hematocrit could not be studied. Use of rhEPO till now might have been limited to severe or complicated anemia or cases requiring rapid reconstitution of the red blood cell pool, such as women with placenta previa, Jehovah's Witnesses with anemia, or special subgroups such as those with thalassemia or sickle cell disease..$^{11,26,27}$

However in recent times rhEPO is being increasingly used as a second line therapy if iron alone fails to increase the hematocrit within a defined interval. Because blood transfusions are a last resort, alternative strategies such as rhEPO plus parenterally administered iron are of considerable interest.

Our study also showed that adjuvant rhEPO combined with an optimized dosage schedule shortens treatment considerably while avoiding the gastrointestinal side effects and associated poor compliance found in as many as $30 \%$ of patients receiving oral therapy.

\section{CONCLUSION}

To conclude, iron sucrose plus rhEPO is an effective treatment for iron deficiency anemia in pregnancy probably because of a synergistic action, with rhEPO stimulating erythropoiesis and iron sucrose most effectively delivering iron for hemoglobin synthesis. Further, our findings of rapid restoration of normal $\mathrm{Hb}$ levels with rapid correction of anemia in all the patients in the case group as well as the absence of significant side effects suggest that this protocol, can be a solution especially when iron supplementation alone fails or in pregnancy near term, where due to time constraints; we have to resort to life saving measures like blood transfusion, which come with its own set of problems. However, further research and evaluation is required to establish its full place, potential and protocol.

Funding: No funding sources

Conflict of interest: None declared

Ethical approval: The study was approved by the Institutional Ethics Committee

\section{REFERENCES}

1. Alper BS, Kimber R, Kudumala Reddy A. Using ferritin levels to determine iron-deficiency anemia in pregnancy. J Fam Pract. 2000;49(9):829-32.

2. Breymann C, Fibach E, Visca E, Huettner C, Huch A, Huch R. Induction of fetal hemoglobin synthesis with recombinant human erythropoietin in anemic patients with heterozygous betathalassemia during pregnancy. J Matern Fetal Med. 1999;8(1):1-7.

3. Hamstra R, Block M, Schocket A. Intravenous iron dextran in clinical medicine. JAMA. 1980;243(17):1726.

4. Macdougall I, Hutton R, Cavill I. Poor response to treatment of renal anemia with erythropoietin corrected by iron given intravenously. $\mathrm{Br}$ Med J. 1989;299(6692):157.

5. Singh K, Fong YF, Kuperan P. A comparison between intravenous iron polymatose complex (ferrum Hausmann) and oral ferrous fumarate in the treatment of iron deficiency anaemia in pregnancy. Eur J Haematol. 1998;60(2):119-24.

6. Breymann C, Major A, Richter C, Huch R, Huch A. Recombinant human erythropoietin and parenteral iron in the treatment of pregnancy anemia: a pilot study. J Perinat Med. 1995;23(1-2):89-98.

7. Adamson JW. Iron deficiency and other hypoproliferative anemias. In: Braunwald E, Fauci AS, Kasper DL, editors. Harrison's textbook of internal medicine. 17th ed. New York: McGraw Hill; 2008: 628-33.

8. Van Wyck DB. Safety and efficacy of iron sucrose in patients sensitive to iron dextran: North American clinical trial. Am J Kidney Dis. 2000;36(1):88-97.

9. Allen LH. Anemia and iron deficiency: effects on pregnancy outcome. Am J Clin Nutr. 2000 May; 71(5 Suppl):1280S-4S.

10. Makrydimas G, Lolis D, Lialios G, Tsiara S, Georgiou I, Bourantas KL. Recombinant human erythropoietin treatment of postpartum anemia: preliminary results. Eur J Obstet Gynecol Reprod Biol. 1998;81:27-31. 
11. Braga J, Marques R, Branco A, Gonçalves J, Lobato L, Pimentel JP, et al. Maternal and perinatal implications of the use of human recombinant erythropoietin. Acta Obstet Gynecol Scand. 1996;75(5):449-53.

12. Harris SA, Payne G Jr, Putman JM. Erythropoietin treatment of erythropoietin-deficient anemia without renal disease during pregnancy. Obstet Gynecol. 1996;87(5 Pt 2):812-4.

13. Juncà $\mathrm{J}$, Vela $\mathrm{D}$, Orts M, Riutort N, Feliu E. Treating the anaemia of a pregnancy with heterozygous $\beta$ thalassemia with recombinant human erythropoietin(r-HuEPO). Eur J Haematol. 1995;55(4):277-8.

14. Danko J, Huch R, Huch A: Epoetin - alfa for treatment of postpartum anemia. Lancet. 1990;335(8691):737-8.

15. Breymann C, Zimmermann R, Huch R, Huch A. Use of recombinant human erythropoietin in combination with parenteral iron in the treatment of postpartum anemia. Eur J ClinInvest. 1996;26(2):123-30.

16. Junca J, Vela D, Orta M, Riutort N, Feliu E. Treating theanemia of a pregnancy with heterozygous beta thalassaemia with recombinant human erythropoietin ( r-HuEPO). Eur J Haematol. 1995:55(4)-277-8.

17. Bourantas K, Makrydimas G, Georgiou J, Tsiara S, Lolis D. Preliminary results with administration of recombinant human erythropoietin in sickle cell / beta- thalassemia patients during pregnancy . Eur $\mathbf{J}$ Haematol. 1996:56(5):326-8.

18. Breymann C, Visca E, Huch R, Huch A. Efficacy and safety of intravenously administered iron sucrose with and without adjuvant recombinant human erythropoietin for the treatment of resistant iron deficiency anemia during pregnancy. Am J Obstet Gynecol. 2001;184(4):662-7.

19. Sifakis S, Angelakis E, Vardakia E, Koumantaki Y, Matalliotakis I, Koumantakis E. Erythropoietin in the treatment of iron deficiency anemia during pregnancy. Gynecol Obstet Invest. 2001;51(3):150-6.

20. Goodnough LT, Price TH, Rudnick S. Iron-restricted erythropoiesis as a limitation to autologous blood donation in the erythropoietin stimulated bone marrow. J Lab Clin Med. 1991;118(3):289-96.

21. Macdougall IC, Hutton RD, Cavill I, Coles GA, Williams JD. Poor response to treatment of renal anaemia with erythropoietin corrected by iron given intravenously. BMJ. 1989;299(6692):157-8.

22. Cazzola M, Mercuriali F, Brugnara C. Use of recombinant human erythropoietin outside the setting of uremia. Blood. 1997;89(12):4248-67.

23. Goldstein JD, Garry DJ, Maulik D. Obstetric conditions and erythropoietin levels. Am J Obstet Gynecol. 2000;182(5):1055-7.

24. Beguin Y, Lipscei G, Thoumsin H, Fillet G. Blunted erythropoietin production and decreased erythropoiesis in early pregnancy. Blood. 1991;78(1):89-91.

25. Fuchs D, Weiss G, Werner-Felmayer G, Wachter H. Erythropoietin and decreased erythropoiesis in pregnancy. Blood. 1992;79(2):533.

26. Hudon L, Belfort MA, Broome DR. Diagnosis and management of placenta percreta: a review. Obstet Gynecol Surv. 1998;53:509-17.

27. Vora M, Gruslin A. Erythropoietin in obstetrics [published erratum appears in Obstet Gynecol Surv 1998;53:736]. Obstet Gynecol Surv. 1998;53(8):5008.

Cite this article as: Sandhu N, Singh S. Role of IV administered Iron sucrose with recombinant erythropoietin in the treatment of moderate and severe iron deficiency anemia in the third trimester of pregnancy. Int J Reprod Contracept Obstet Gynecol 2019;8:3332-8. 